DOI: 10.12731/2070-7568-2017-2-88-101

УДК 327.56

\title{
ТЕРРИТОРИАЛЬНЫЕ ПРЕТЕНЗИИ К СОВРЕМЕННОЙ РОССИИ
}

\section{Харыбин А.Н.}

В статье автором исследуются территориальные претензии к современной России со стороны других государств. Автор отмечает, что в политической науке нет четкого определения понятия «территориальный конфликт», зачастую как синонимы к нему используются термины «международньй конфликт», «территориальный спор». В статье предложено оригинальное толкование понятия «территориальный конфликт», показаны его основные отличия от территориальных споров. Во второй части статьи автор изучает территориальные конфликты с участием России и предлагает их классификацию на основе трех признаков: географический, масштаб, способ. Выделены семь основных направлений конфликтов: западное, балканское, южное, центрально-азиатское, юго-восточное, восточное, северное. Исследована вероятность возникновения новых конфликтов и опасность данных направлений для России. В конце статьи предложена универсальная схема классификачии конфликтов, на которой отображены современные территориальные конфликты России и Китая, а так же проведен краткий сравнительный анализ конфликтов двух стран.

Ключевые слова: Территориальныле конфликты; Россия; Война; Территориальный спор; Китай; Граница; Международные конфликтыл; Страна; Украина; Запад.

\section{TERRITORIAL CLAIMS TO RUSSIA TODAY}

\section{Kharybin A.N.}

In the article the author examines territorial claims to modern Russia from other countries. The author notes that in political science 
there is no clear definition of "territorial conflict", often as synonyms to it uses the terms "international conflicts", "territorial dispute". The article offers an original interpretation of the concept of "territorial conflict", showing its main differences from territorial disputes. In the second part of the article the author examines the territorial conflicts involving Russia and offers their classification on the basis of three characteristics: geographical, scale, method. Highlighted seven main areas of conflict: the Western, the Balkan, South, Central Asian, South-East, East, North. The author calculate the probability of new conflicts and the danger of these areas to Russia. At the end of the article proposed a universal scheme of classification of conflicts, which displays modern territorial conflicts with Russia and China, as well as a brief comparative analysis of the conflicts between the two countries.

Keywords: Territorial conflicts; Russia; War; Territorial dispute; China; Border; International conflicts; A country; Ukraine; West.

В политической науке имеется проблема четкости определения понятия «территориальный конфликт»: большинство публикаций, изучающих данный феномен либо не указывают, какой смысл вкладывается в данную категорию [9, с. 416], либо используют определение, взятое из словаря психологии и педагогике и адаптированное применительно к политической сфере, трактующее территориальный конфликт как разновидность межгосударственного конфликта, объектом которого является территория [11]. Так же многие исследователи используют понятие территориальный спор [17] или международный конфликт [8, с. 9], используя его как синоним слову территориальный конфликт. Однако определение из арсенала психологии не всегда уместно использовать в политической науке, а территориальный спор и территориальный конфликт являются разными понятиями.

Если обратиться к этимологии слов спор и конфликт, то «спор» это словесное состязание, обсуждение чего-либо двумя или несколькими лицами, в котором каждый отстаивает свое мнение [18]. 
«Конфликт» - это столкновение противоположных сторон, мнений, сил, политическое значение - осложнение в международных отношениях [10].

То есть различие между двумя понятиями заключается в том, что спор - словесная риторика, а конфликт - конкретные шаги, влекущие за собой осложнение в международных отношениях. Так же для понимания различий необходимо упомянуть о еще двух важных моментах:

1. Признание сторонами.

Если понятие спор предполагает наличие как минимум двух субъектов - спорящих, каждый из которых участвует и признает спор (в противном случае диалог превращается в монолог), то конфликт необязательно признается сторонами. Может быть только один активный субъект, вторая сторона вполне может не предпринимать никаких действий или не признавать конфликт. К примеру, Россия не признала свое участие в конфликте на юго-востоке Украины, а так же наличие конфликта вокруг полуострова Крым: по словам пресс-секретаря президента РФ Д. Пескова: «Вопроса о принадлежности Крыма не существует» [7], аналогичная ситуация с Курильскими островами [16]. Как отсутствие действий одной из сторон в качестве примера, можно привести пассивность Украины в момент перехода Крымского полуострова под суверенитет России: шаги были запоздалыми, что признается в том числе и проукраинскими общественными деятелями [15].

2. Разрешение.

Спор может:

а) превратиться в конфликт, если стороны перейдут «от слов к делу»;

б) затухнуть;

в) разрешиться мирным путем.

У конфликта же дополнительно может появиться еще один способ: силовой.

Можно дать следующее определение территориального конфликта - столкновение двух или более сторон по поводу какой- 
либо территории, влекущее за собой осложнение международной обстановки, необязательно признающееся участниками. При этом конфликт может быть решен силовым путем.

История России богата на различные территориальные конфликты, это связанно с положением России как «большого пространства», которое может наносить и получать удары по всему периметру своих границ [3, с. 42], что достаточно часто случалось в истории. К примеру, во время неблагоприятной военной ситуации на западной границе (Ливонская война, Польская интервенция), Россия одновременно успешно продвигалась на востоке. Во время войны 1812 года с Наполеоном, на южном направлении у России одновременно шла война с Персией. Наиболее показательным моментом является Крымская война, когда Франция и Великобритания одновременно смогли атаковать Россию по всему периметру границ.

В данной статье предлагается универсальная классификация территориальных конфликтов России на основе трех признаков:

1. Направление конфликта.

2. Масштаб конфликта.

3. Способ ведения конфликта.

Направление конфликта - фактор, разделяющий конфликты на основе территории. Выделяются следующие направления:

- Западное;

- Балканское;

- Южное;

- Центрально-азиатское;

- Восточное;

- Юго-восточное;

- Северное.

В каждом из семи направлений Россия проводила различную политику, и образ России воспринимался по-разному.

Западное направление - Россия воспринимается как враг, сильна русофобия, продвижение достаточно затрудненно, цель России - отражение агрессии и по возможности приобретение новых территорий. 
Балканское - Россия выступает как страна-освободитель, главная цель: проливы Босфор и Дарданеллы, которые, с одной стороны, позволят выйти к незамерзающим морям и мировым транспортным коммуникациям, а так же снимут вопрос безопасности южных рубежей России, а с другой являются историческим сакральным образом «Второго Рима», к воссоединению с которым «Третий Рим» стремился на протяжении всей своей истории. Тактика, которая для этого использовалась, заключалась в создании лояльных России политических режимов на Балканах, а так же взятия под контроль территории православной цивилизацией.

Южное направление - Россия присоединяет территории, которые входят в состав империи либо добровольно (и воспринимают Россию как освободителя), либо в ходе ожесточенного сопротивления. Однако независимо от способа включения местные элиты становятся частью правящего класса России, а местное население сохраняет лояльность новым властям.

Центрально-азиатское направление: продвижение России идет одновременно с колонизацией, заселением этническими русскими, созданием инфраструктуры, изменением традиционного уклада жизни (Монголия: «из феодализма в социализм»).

Восточное направление: обретение независимости от Золотой Орды, подчинение себе ее осколков, экспансия и колонизация территории Сибири и Дальнего Востока. При этом не нарушается традиционный уклад жизни, продвижение идет в том числе и мирным путём, на общем фоне выделяется взятие Казани, но при этом уместно вспомнить, что до этого она практически весь период своего существования находилась в сфере влияния Москвы. После падения столицы Казанское Ханство быстро прекратило свое существование, территория и проживающие на ней народы вошли в состав России. Выделялась история присоединения к империи чукотских племен, которые в результате безуспешных попыток силового принуждения, были включены в добровольном порядке [5, с. 26]. 
Юго-восточное направление: единственное направление, где Россия после первоначальной экспансии перешла к обороне и только защищалась, уступая территории, что можно наблюдать и сейчас: демаркация границы с Китаем и его новые территориальные претензии, проблема Курильских островов.

Северное направление: наиболее неактивное, здесь Россия довольно быстро достигла естественных геополитических рубежей, а в силу слабозаселенности, суровых условия для жизни, удаленности не встречала конкурентов. Однако в связи с глобальными изменениями в климате, а так же наличием богатых ресурсов, роль Арктики все больше возрастает. При этом если раньше естественной границей был берег, то теперь в связи с проблемой определения континентального шельфа возникает проблема определения границ государств, что в среднесрочной перспективе несет серьезную угрозу территориальных конфликтов.

Если исходить из установки Х. Маккиндера, что Россия пространство, которое может получать и наносить удары со всех сторон, с активизацией деятельности различных государств в Арктике последняя сторона России, которая была относительно защищена от посягательств других держав перестанет быть таковой.

После распада СССР Россия участвовала в шести территориальных конфликтах, которые соответствуют основным направлениям:

- Западное - конфликт в Приднестровье и конфликт с Украиной;

- Балканское - опосредованное участие Югославских войнах без прямого территориального интереса России;

- Южное - Чечня и Грузия;

- В Средней Азии Россия решила не идти на конфликт по поводу территории Северного Казахстана, хотя предпосылки для этого имелись

- Юго-восточное - Россия заняла традиционную пассивно-оборонительную позицию как по отношению к Китаю, и в итоге решила старый конфликт с советских времен мирно, путем уступок, так и по отношению к Японии - Курильские острова. 
- На Севере и Востоке в современной истории России конфликтов не было.

Так же представляется уместным составить список, в котором географические направления будут расставлены по степени конфликтности, с целью понимания необходимости правильного распределения сил и ресурсов:

1. Западное - самое конфликтогенное и опасное: традиционная сильная русофобия, враждебные государства, сильные противники. Как результат - на данном направлении возник конфликт с Украиной, участниками которого являются не столько Россия и Украина, сколько Россия и Запад во главе с США [2, с. 71]. С точки зрения классической геополитики, данный конфликт можно рассматривать как противостояние «Цивилизации Суши» и «Цивилизации Моря» за «Берег», то есть это глобальный, за мировое господство, территориальный конфликт. При этом Украина, как отмечает М.Б. Погребинский, выступает как «приз» в войне [12, c. 346].

2. Юго-восточное - исторически наиболее слабое направление российской политики.

3. Центрально-азиатское - основная проблема связанна с исламизацией Центральной Азии, уменьшением роли русского языка [6, с. 87], а так же с постепенным уходом с властных постов пророссийских политических лидеров. При отсутствии четких механизмов передачи власти это повлечет серьезную политическую нестабильность и социальные потрясения. При этом Центральная Азия рассматривается США стратегическим плацдармом в случае эвентуальной конфронтации с Россией [4, с. 28].

4. Южное направление - в первую очередь проблема катастрофического падения доли русскоязычного населения, которое является проводником интересов Центра, а так же наличие старых, «замороженных» конфликтов, которые сейчас находятся в латентной фазе и вполне могут возобновиться при малейшем ослаблении влияния Москвы, как это было в начале 90-х годов XX века. Так же серьезную опасность представляет то, что в на- 
циональных республиках развивается радикальная ветвь ислама, и, несмотря на усилия властей, пресечь этот процесс пока не удается [14, с. 57].

5. Северное направление - связанно с усилением значения Арктики в международных отношениях, а так же важностью энергоресурсов Арктики, особенно для европейских стран [1].

6. Балканское направление - здесь маловероятно участие России в будущих конфликтах, страны Балкан в целом переориентировались на Европу. Сербия, остающаяся последней пророссийской страной в регионе, так же стремится к вступлению в Европейский Союз, вопрос же черноморских проливов для России закрыт в связи с усилением Турции. То есть Россия потеряла данное направление и не будет участвовать в политике региона как активный игрок.

7. Дальневосточное направление - здесь для России нет угроз, естественная граница достигнута, земли в составе России не представляют особого интереса для геополитических конкурентов.

Второй критерий классификации - масштаб, здесь уместно использовать классическую схему:

- конфликты локальные, не оказывающие серьезного влияния на Россию, расстановку сил в мире (пятидневная война 2008 года);

- конфликты региональные, изменившие ситуацию на территории большого пространства (Крымская война, война в Афганистане);

- конфликты глобальные, борьба за мировое господство (Наполеоновские войны, Вторая Мировая, Холодная война).

Тип конфликтов:

1. Вооруженные столкновения.

2. Война.

3. Давление без применения вооруженной силы.

4. Невоенное вмешательство, дестабилизация политических режимов извне, без прямого участия (гражданские войн, попытки переворотов, поддержка антиправительственных сил, террористические акты). 
При этом как отмечает профессор И.Л. Морозов, в современной международной системе происходит неуклонное повышение роли третьего и четвертого из перечисленных выше факторов [13, c. 127].

Данная классификация конфликтов будет отражена на следующей схеме территориальных конфликтов России после распада СССР (см. Рис. 1):

Война

Боевые действия

Давление

Невоенное вмешательство
Локальный

Региональный

Глобальный

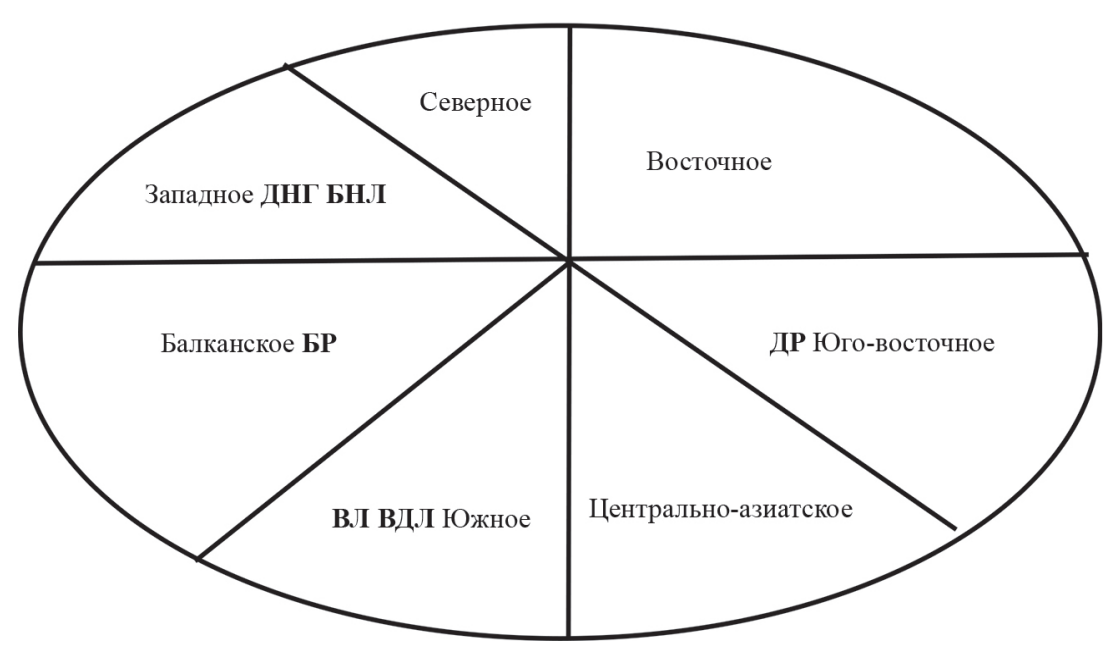

Рис. 1. Территориальные конфликты России после распада СССР

При этом данная схема является универсальной: с помощью нее можно рассмотреть конфликты России на любом этапе или на всем протяжении ее истории, понять какие территории являются тылом (сейчас Северо-Восток). А так же любой другой страны, с необходимостью правильно обозначить географические направления, которые являются главным фактором градации. К примеру, территориальные конфликты Китая (Рис. 2): 
Война

Боевые действия

Давление
Локальный

Региональный

Глобальный

Невоенное вмешательство

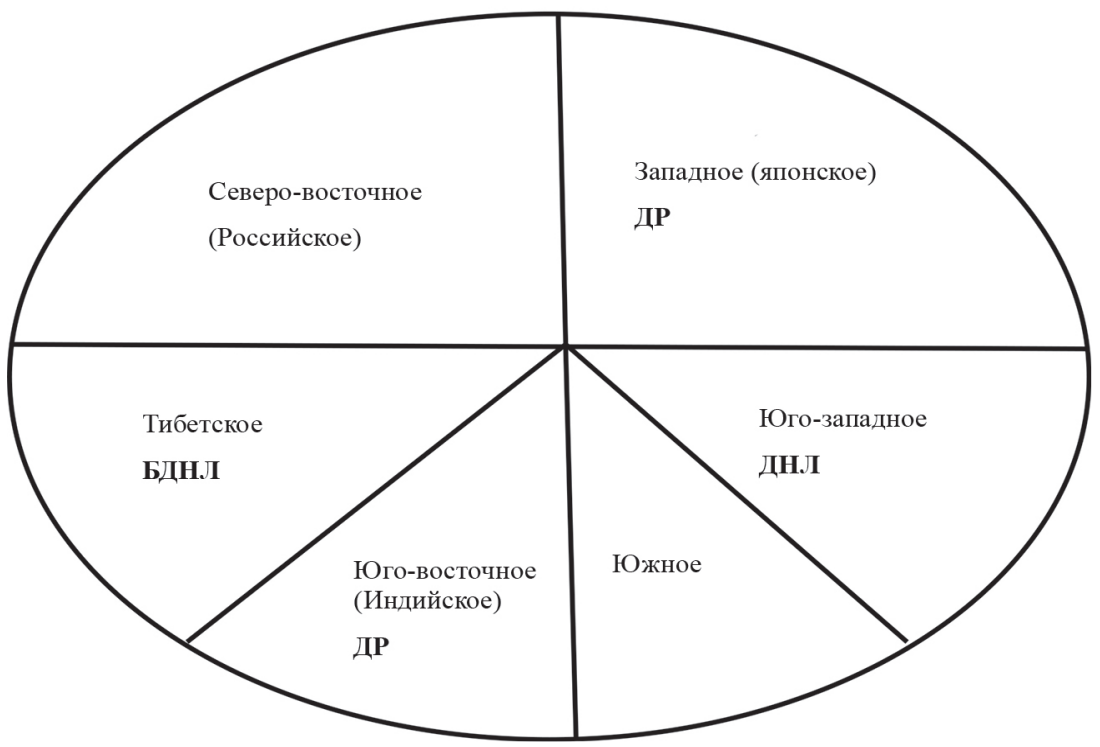

Рис. 2. Территориальные конфликты Китая на современном этапе

Если сравнить Китайские и Российские конфликты, можно сделать следующие выводы:

1. Для обеих стран северо-восточное направление является стабильным и бесконфликтным.

2. У Китая, в отличие от России отсутствует глобальное противостояние.

3. В целом Китай характеризует меньшее количество конфликтов.

4. Если для России главная угроза конфликтов на Западе, при возможности потенциальных конфликтов по всему периметру, то у Китая можно выделить два основных фронта: японский и тибетско-индийский. 


\section{Список литературы}

1. Climate change may spark conflict with Russia, EU told// Guardian. 2008. March 10.

2. Багнюк В.Е. Конфликтологический анализ критической геополитики // Социум и власть. 2016. №3 (59). С. 67-72.

3. Дугин А. Основы геополитики [текст]: учебник. Москва: Арктогея, 2000. $126 \mathrm{c}$.

4. Земсков В.Н. Стратегия США в Центральной Азии // Вестник МГИМО. 2013. №2 (29). С. 28-32.

5. Зуев А.С. Русско-чукотские переговоры 1778 года и принятие чукчей в подданство России // Вестник Новосибирского Государственного Университета. Серия: история, филология. 2006. Т.5 №3-1. C. 26-37.

6. Казанцев А.А., Гусев Л.Ю. Продвижение «Мягкой силы» России в Центральной Азии как инструмент развития евразийской экономической интеграции // Управленческое консультирование. 2015. №11 (83). С. 80-91.

7. Какими средствами Украина будет пытаться вернуть Крым. Политика. ИноСМИ - Все, что достойно перевода [Электронный ресурс]. Режим доступа: http://inosmi.ru/politic/20160131/235223328. html (Дата обращения 18.12.2016).

8. Камкия Б.А. Контекстуальный подход в политологии в конце ХХ века // Научный вестник Волгоградского филиала РАНХиГС. Серия: политология и социология, 2015. №2. С. 4-14.

9. Киреева A.А. Геополитическое противостояние между велики державами в восточной Азии // Конфликтология, 2014. №S. С. 415-418.

10. Конфликт - Викисловарь. [Электронный ресурс]. Режим доступа: https://ru.wiktionary.org/wiki/ (Дата обращения 18.12.2016).

11. Конфликт территориальный - это... Что такое конфликт территориальный? [Электронный ресурс]. Режим доступа: http://psychology_ pedagogy.academic.ru/ (Дата обращения 18.12.2016).

12. Лесная Г.М. Международная конференция «Российско-украинские отношения: реалии и перспективы» // Вестник МГИМО Университета, 2013. №4 (31). С. 343-347. 
13. Морозов И.Л. Безопасность политических коммуникаций в современной России // Вестник ВолГУ. Серия 4, История. Регионоведение. Международные отношения. 2013. № 1 (23). С. 127-131.

14. Морозов И.Л. Трансформация политического радикализма - от «Революционного карнавала» к религиозному терроризму // Наука Красноярья, 2016. № 4. С. 46-61.

15. Оккупация Крыма и Донбасса. Поражает дикая пассивность и безответственность украинских властей - правозащитник. Национальный антикоррупционный портал «АНТИКОР» [Электронный pecypc]. Режим доступа: http://antikor.com.ua (Дата обращения 18.12.2016).

16. Путин - у России нет территориальных споров с Японией // НТВ. RU [Электронный ресурс]. Режим доступа: http://www.ntv.ru/ novosti/1732017/ (Дата обращения 18.12.2016).

17. Райков Ю.А. Территориальные противоречия и безопасность в Восточной Азии // ЮВА: актуальные проблемы развития. 2015. №28. C. 20-34.

18. Спор - Викисловарь. [Электронный ресурс]. Режим доступа: https:// ru.wiktionary.org/wiki/\%D1\%81\%D0\%BF\%D0\%BE\%D1\%80 (Дата обращения 18.12.2016).

\section{References}

1. Climate change may spark conflict with Russia, EU told. Guardian. 2008. March 10.

2. Bagnjuk V. E. Konfliktologicheskij analiz kriticheskoj geopolitiki [Conflictological analysis of critical geopolitics]. Socium i vlast'. 2016. №3 (59), pp. 67-72.

3. Dugin A. Osnovy geopolitiki [The foundations of geopolitics]. Moskva: Arktogeja, 2000. 126 p.

4. Zemskov V.N. Strategija SShA v Central'noj Azii [US strategy in Central Asia]. Vestnik MGIMO. 2013. №2 (29), pp. 28-32.

5. Zuev A.S. Russko-chukotskie peregovory 1778 goda i prinjatie chukchej v poddanstvo Rossii [Chukchi-Russian negotiations of 1778 and the adoption of the Chukchi in Russian citizenship]. Vestnik Novosibir- 
skogo Gosudarstvennogo Universiteta. Serija: istorija, filologija. 2006. V.5 №3-1, pp. 26-37.

6. Kazancev A.A., Gusev L.Ju. Prodvizhenie «Mjagkoj sily» Rossii v Central'noj Azii kak instrument razvitija evrazijskoj jekonomicheskoj integracii [Promotion of "Soft power" of Russia in Central Asia as a tool for the development of Eurasian economic integration]. Upravlencheskoe konsul'tirovanie. 2015. №11 (83), pp. 80-91.

7. Kakimi sredstvami Ukraina budet pytat'sja vernut' Krym [What means Ukraine will try to regain the Crimea]. Politika. InoSMI. Vse, chto dostojno perevoda. http://inosmi.ru/politic/20160131/235223328.html (accessed 18.12.2016).

8. Kamkija B.A. Kontekstual'nyj podhod v politologii v konce XX veka [Contextual approach in political science in the late twentieth century]. Nauchnyj vestnik Volgogradskogo filiala RANHiGS. Serija: politologija i sociologija. 2015. № 2, pp. 4-14.

9. Kireeva A.A. Geopoliticheskoe protivostojanie mezhdu veliki derzhavami v vostochnoj Azii [Geopolitical confrontation between the great powers in East Asia]. Konfliktologija, 2014. №5. S. 415-418.

10. Konflikt [Confrontation] Vikislovar'. https://ru.wiktionary.org/ (accessed 18.12.2016).

11. Konflikt territorial'nyj - jeto... [The territorial conflict is...] Chto takoe konflikt territorial'nyj? http://psychology_pedagogy.academic.ru/ (accessed 18.12.2016).

12.Lesnaja G.M. Medunarodnaja konferencija «Rossijsko-ukrainskie otnoshenija: realii i perspektivy» [International conference "Russian-Ukrainian relations: realities and prospects"]. Vestnik MGIMO Universiteta, 2013. №4 (31), pp. 343-347.

13. Morozov I.L. Bezopasnost' politicheskih kommunikacij v sovremennoj Rossii [Security political communication in contemporary Russia]. Vestnik VolGU. Serija 4, Istorija. Regionovedenie. Mezhdunarodnye otnoshenija, 2013. №1 (23), pp. 127-131.

14. Morozov I.L. Transformacija politicheskogo radikalizma - ot «Revoljucionnogo karnavala» $\mathrm{k}$ religioznomu terrorizmu [Transformation of political radicalism - from the "Revolutionary carnival" to religious terrorism]. Nauka Krasnojar'ja, 2016. №4, pp. 46-61. 
15. Okkupacija Kryma i Donbassa. Porazhaet dikaja passivnost' i bezotvetstvennost' ukrainskih vlastej [The occupation of the Crimea and the Donbass. Affects wild the passivity and irresponsibility of the Ukrainian authorities and human rights activist]. Nacional'nyj antikorrupcionnyj portal «ANTIKOR». http://antikor.com.ua (accessed 18.12.2016).

16. Putin - u Rossii net territorial'nyh sporov s Japoniej [Putin - Russia has no territorial disputes with Japan]. NTV.RU. http://www.ntv.ru/novosti/1732017/ (accessed 18.12.2016).

17. Rajkov Ju.A. Territorial'nye protivorechija i bezopasnost' v Vostochnoj Azii [Territorial disputes and security in East Asia]. JuVA: aktual'nye problemy razvitija. 2015. №28, pp. 20-34.

18. Spor [Dispute] Vikislovar'. https://ru.wiktionary.org/wiki/\%D1\%81\%D0\%BF\%D0\%BE\%D1\%80 (accessed 18.12.2016).

\section{ДАННЫЕ ОБ АВТОРЕ}

Харыбин Александр Николаевич, ассистент кафедры «Философия, Политология и Право» ВолГАУ, аспирант ВИУ РАНХиГС Волгоградский государственный аграрный университет; Волгоградский Институт Управления Российской академии народного хозяйства и государственной службы при Президенте Российской Федеращии.

пр-т Университетский, 26, г. Волгоград, 400002, Российская Федерации; ул. Гагарина, 8, г. Волгоград, 400131, Российская Федерациия.

xahaleksandr@mail.ru

\section{DATA ABOUT THE AUTHOR}

Kharybin Aleksander Nikolaevich, Assistant in the Department of "Philosophy, Political science and law", Graduate Student Volgograd State Agrarian University; Volgograd Institute of Management of the Russian Academy Of National Economy and Public Administration under the President of the Russian Federation 26, Universitetsky Ave., Volgograd, 400002, Russian Federation; 8, Gagarin Str., Volgograd, 400131, Russian Federation xahaleksandr@mail.ru 